\title{
HUMAN RIGHTS MECHANISMS IN SMALL PACIFIC STATES: IMPLICATIONS FOR DIALOGUE ABOUT REGIONAL HUMAN RIGHTS MECHANISMS
}

Joy Liddicoat*

This article draws on research conducted by the New Zealand Human Rights Commission and the Pacific Islands Forum Secretariat in regard to opportunities and challenges for national human rights mechanisms in small Pacific states. The author uses this research to highlight some of the issues and concerns in regards to the development of a regional human rights initiative. Suggestions are provided for the process to be used when engaging in dialogue regarding the implementation and development of a regional human rights mechanism.

\section{INTRODUCTION}

Increased engagement with international human rights standards and mechanisms by Pacific states $^{1}$ over the last decade has raised questions about the effectiveness and appropriateness of existing national systems for protection and promotion of human rights in Pacific states and territories. There has been comparatively little research about national human rights mechanisms and still less in relation to small Pacific states. ${ }^{2}$ In 2005 the New Zealand Human Rights Commission and the Pacific Islands Forum (PIF) Secretariat with funding assistance from the New Zealand International Aid and Development Agency addressed this information gap by agreeing to

* Commissioner, New Zealand Human Rights Commission. The views expressed in this paper are the author's own.

1 For the purposes of this paper "small Pacific states" excludes Australia and New Zealand.

2 See, for example, the PIF Members Regional Workshop on National Human Rights Mechanisms (Suva, 2005) [PIF Members Regional Workshop]. 
carry out a research and dialogue project in the region. ${ }^{3}$ Dialogue with informants in Tuvalu, Samoa, Niue, and Palau identified both opportunities and challenges for human rights mechanisms in small Pacific states. ${ }^{4}$ The research also shows that while small Pacific states have opportunities to give their own unique Pacific expression to international human rights standards for human rights mechanisms, their desire to do so is tempered by caution. ${ }^{5}$

At the Symposium, participants endorsed efforts to consider a regional human rights commission, seeing this as a further development in building human rights mechanisms in the region. However, participants acknowledged that for Pacific states it is not simply a case of either national or regional human rights mechanisms and that work on the establishment of a regional commission should also proceed in conjunction with further work on the establishment of national institutions. It was agreed that specific context is a crucial factor which can influence the broader discussion around national institutions and a regional mechanism. ${ }^{6}$ This paper draws upon evidence from the research and dialogue project with Pacific states to highlight some issues and concerns which may assist the emerging discussion about regional human rights mechanisms.

\section{BACKGROUND TO THE RESEARCH PROJECT}

The challenges of distance, dispersal and relatively small size were key reasons for the decision by the PIF Secretariat and the New Zealand Human Rights Commission to assist Pacific states by carrying out the research and dialogue project in 2006 and 2007. The project supported the April 2004 decision of PIF Leaders to "encourage the development of national human rights machinery". ${ }^{7}$ A related objective was to assist in stimulating and informing debate and discussion about the establishment of practical human rights mechanisms both within states and the Pacific region.

Three concerns consistently emerged during dialogue with regional stakeholders about human rights in the Pacific. These concerns reflect the broader geographical context of the Pacific region, including the large number of small island states compared to some other regions, as well as the particular contexts of individual states. Those three concerns are: ${ }^{8}$

(1) How human rights standards can be met given the already high level of competing demands on limited resources;

3 See Joy Liddicoat National Human Rights Institutions: Pathways for Pacific States (Pacific Human Rights Issues Series: 1 New Zealand Human Rights Commission and PIF Secretariat, Fiji and New Zealand, 2007). Ibid, 17-24.

5 Ibid, 4.

6 Final Statement (Strategies for the Future: Protecting Rights in the Pacific, in this volume).

7 The Pacific Plan for Strengthening Regional Co-operation and Integration (PIF Secretariat, Suva, Fiji, October 2007) www.forumsec.org (accessed 1 June 2008).

8 PIF Members Regional Workshop, above n 2, 7. 
(2) The obligations imposed by ratification of international human rights instruments; and

(3) The relationship between custom and human rights.

The specific focus of this research and dialogue was the first of these concerns, although, where possible, the two related concerns were also considered.

\section{METHODOLOGY}

The dialogue project was in three phases: research (including in-country consultation), preparation of a draft research paper and follow up in-country dialogue. In-country consultations were carried out using a process of mutual information sharing to ensure that concerns about the high level of demand upon countries with scarce resources were properly understood. Consultations took place with Government agencies, political leaders, civil society organisations and other interested agencies and individuals. After seeking expressions of interest from PIF countries, initial in-country consultations were undertaken in Samoa, Niue, and Tuvalu.

A draft research paper was subsequently prepared based on in-country consultations, a literature review, legal research, and discussions with key informants. The draft was circulated to PIF members, civil society organisations, key stakeholders and individuals in the region, with comments incorporated into the final publication. The research paper, National Human Rights Institutions: Pathways for Pacific States was subsequently published. Follow-up dialogue took place at a regional meeting of Pacific Islands Members of Parliament in Auckland in 2007 and in Palau in 2008. Taken together, the results were used both to build understanding about prospects and challenges for human rights promotion and protection in the Pacific and as a basis for developing practical suggestions for pathways forward.

The application of a rights-based approach was a critical methodological consideration. ${ }^{9}$ This approach comprised of six elements:

(1) Identification of the human rights of all involved and, in the case of conflict, the balancing of the various rights to maximise respect for all rights and right-holders;

(2) The participation of individuals and groups in decision-making;

(3) Accountability for actions and decisions, which allows individuals and groups to complain about decisions that affect them adversely;

(4) Non-discrimination among individuals and groups through equal enjoyment of rights and obligations;

9 Human Rights Commission Human Rights in New Zealand Today Nga Tika Tangata O Te Motu (Human Rights Commission, New Zealand, 2004) 9-10. 
(5) Empowerment of individuals and groups by allowing them to use rights as leverage for action and to legitimise their voice in decision-making; and

(6) Linking of decision-making at every level to agreed human rights standards.

The rights-based approach makes transparent the relationships between states and their peoples. In particular, the approach recognises that for rights to be meaningful, mechanisms for their exercise must exist in practice and these must function effectively. The rights-based approach recognises that states' obligations to respect, protect and promote human rights imposes a duty to provide protective mechanisms. States are therefore obliged to develop and maintain mechanisms for promotion and protection of human rights. ${ }^{10}$

\section{PACIFIC PATHWAYS - REGIONAL CONTEXT AND KEY HUMAN RIGHTS ISSUES}

Research participants considered that progress towards establishing national mechanisms must be guided by the particular human rights issues and priorities in each state and the overall regional context. ${ }^{11}$ Participants noted that the region faces significant human rights issues in relation to employment, freedom from discrimination, protection and equal treatment of women, children, people with disabilities, and those living with HIV/AIDS, the right to health, environmental degradation, the rights of those detained, and incidents related to tribal or land disputes. ${ }^{12}$ There was a desire for more progress to promote and protect human rights, provided this progress took account of the context and concerns of small island states.

An emphasis was placed on participatory processes for Pacific contexts. For example, it was considered that dialogue about forms of national mechanisms should take account of, and have respect for, human rights promotion currently being carried out by women's organisations and other groups and ensure participation of women, young people, disabled people and vulnerable or marginalised groups. ${ }^{13}$ In addition, efforts should be made to build upon work by the media to promote human rights, with account taken of the need to ensure promotion is accessible in the languages and media appropriate for Pacific peoples. ${ }^{14}$

Consultations in Tuvalu and Samoa highlighted both the traditional and modern strengths of Pacific peoples. These included traditional values which are closely linked to the importance of

10 Human Rights Commission Human Rights in New Zealand Today Nga Tika Tangata O Te Motu (Human Rights Commission, New Zealand, 2004) 22.

11 PIF Members Regional Workshop, above n 2, 24.

12 Ibid, 14-15.

13 Ibid, 25.

14 Ibid. 
family relationships, resilience, the sharing of resources and a co-operative approach to economic and social activity. Participants considered these strengths should be acknowledged and drawn upon in any dialogue about national mechanisms. ${ }^{15}$

\section{A Existing Human Rights Protections}

Mechanisms for human rights protection can, and do, take a variety of forms both within Pacific states and across the region. These forms include cultural systems such as village or island councils, justice systems including courts and the judiciary, specific human rights institutions such as national human rights institutions, or executive or parliamentary systems such as human rights promotion or education functions within a Government department. ${ }^{16}$ Where established, the nature and scope of functions carried out by national human rights institutions is guided by a set of international accreditation standards known as the "Paris Principles". ${ }^{17}$ There are currently no accredited national human rights institutions in small Pacific states. Taking these existing mechanisms for human rights protection into account, the research and dialogue project sought to explore issues related to national institutions and other human rights machinery.

Dialogue participants emphasised that a range of mechanisms for human rights promotion and protection are already in place both nationally and across the region. There were concerns that any additional new mechanisms should take into account the variety of mechanisms in the Pacific which provided a broad, if fragmented, infrastructure for human rights protection and promotion. Participants noted that established forms of infrastructure fell into six broad categories: ${ }^{18}$

(1) National constitutions: many Pacific countries have constitutional documents which guarantee fundamental human rights and incorporate the principle of the rule of law including Papua New Guinea, Vanuatu, Nauru, the Republic of the Marshall Islands, Fiji, Kiribati, Samoa, Solomon Islands and Tuvalu.

(2) Parliamentary systems: Pacific expressions of the parliamentary foundations of democracy do vary, but are generally underpinned by respect for electoral participation and contested national elections.

(3) Governance structures and systems: national laws, regulations, government policies, and service delivery through Government administration provide the foundations for machinery through which human rights can be delivered by Government agencies. These

15 Ibid, 24.

16 Ibid, 11-14.

17 Principles Relating to the Status and Functioning of National Institutions for the Protection and Promotion of Human Rights UNGA Res 48/134 (20 December 1993).

18 PIF Members Regional Workshop, above n 2, 11-14. 
structures and systems include ministerial offices, leadership codes, public sector codes of conduct, and other policies and practices related to the exercise of governance powers.

(4) Legal systems: legal systems to support the rule of law vary including both traditional courts and associated legal systems and judicial court systems.

(5) Active civil society: civil society groups, including non-governmental organisations, exist throughout the region and play an active role in critical analysis of and advocacy for promotion and protection of human rights.

(6) Regional infrastructure and initiatives: the PIF Secretariat services the PIF and governments of the region. There are inter-government regional agreements as well as multi-lateral and bilateral agreements. Regional and international aid and development agencies operate in the region and increasingly these work with both civil society groups and governments on human rights related matters.

During the research, the implications of relatively restricted resources, combined with the incremental increase in responsibilities assigned to agencies and individuals, emerged as a consistent theme. Participants noted that the current infrastructure could often place unrealistic demands on states for adequate financial and human resources, particularly where the infrastructure of government was small. For example, in Niue, the Secretary for Justice has responsibility for the Ministry of Justice and is also: ${ }^{19}$

(1) Registrar of the Court (including the Land Court and with administrative responsibility for court sessions when the circuit judge visits);

(2) Registrar of Births, Deaths and Marriages;

(3) Registrar of Incorporated Societies; and

(4) Chief Electoral Officer.

Participants emphasised the need to ensure existing mechanisms were adequately supported. For instance, in Niue, reservations were raised about a new and separate mechanism being established when existing mechanisms needed to be further supported and strengthened. Concerns were raised that new institutions would also require personnel, with the result that existing institutions which were short-staffed or under-resourced, would continue to suffer. As one Niuean participant stated, "we don't need a new institution. We need people to help us make things work". 20

Participants considered that many Pacific states do not have the fiscal flexibility to easily ensure that their existing human rights mechanisms are resourced to an optimal level. Many of the costs of

PIF Members Regional Workshop, above n 2, 22-23. 
Government are fixed, such as the cost of parliamentary services, the public service, judicial systems including courts, judicial officers and judicial administration, security such as police and prison services, and provision of health and education services, social services, international security and foreign affairs. The research and literature review showed that the indivisible nature of these services means that small states can face higher costs per person to provide them. This is exacerbated in the Pacific for those states that comprise islands spread across vast expanses of ocean and the transport, communication and service delivery challenges for those in remote areas.

Participants noted a further tension in this area in small states where small country size meant steps were needed to try to confine the size of the executive to reasonable limits. ${ }^{21}$ In Niue, Tuvalu and Samoa various ministerial portfolios are frequently multi-faceted, placing high demands on ministerial offices. Similar issues arise for administrators and personnel, with a small number of government agencies having broad and often complex responsibilities for both service delivery and policy development. With a small number of personnel and multiple demands, there is limited reserve capacity for new or increasing work demands, which can quickly lead to over-extension. The problem of limited human resources can also be compounded by difficulties in retention or shortages in key occupational areas.

\section{B Action-Oriented Research and Dialogue}

In line with a rights-based approach, the research methodology encouraged informants to engage in a participatory process of identifying practical actions relevant to their own context. Participants suggested a wide range of strategies and practical approaches to deal with the concerns about resource constraints. These included: ${ }^{22}$

(1) Considering economies of scope, rather than scale, so that agencies already working in a particular area, such as health promotion, are able to contribute to efforts for human rights promotion and protection;

(2) In light of the physical remoteness of many islands, sharing the costs of human rights promotion and protection, for example, by considering the feasibility of service delivery through or with existing services, rather than new ones;

(3) Pooling existing resources to avoid duplication of effort and ensuring the best use of existing expertise;

(4) Allocating priorities for new resource allocation based on what is already being done well by others, including civil society groups;

21 Ibid, 19-20.

22 Ibid, 24-25, 29 and 32-33. 
(5) Reducing the risks of skill loss by developing human rights expertise amongst wider and more diverse groups including village and island councils, the private sector, and civil society; and

(6) Building human rights into existing processes wherever possible including current planning and budgeting processes so that resources can be planned for, secured and developed over the short, medium, and long term.

A strong emphasis was placed on developing Pacific models by taking a "building blocks" approach and using participatory processes. With scarce resources and competing demands, participants noted that adequate time would be needed to allow for consultation, with care not to overburden communities with demands for consultation or to assume that lack of engagement meant lack of interest. Efficiencies were encouraged wherever possible, for example, establishing a working group of community leaders including use of champions and those who have credibility with government, such as village chiefs and religious leaders. Where these efficiencies were considered, reporting and accountability mechanisms back to communities were still required.

Participants expressed a strong desire for more partnerships between Government and civil society groups in dialogue on human rights mechanisms. ${ }^{23}$ It was suggested that regional resources on human rights should be used as a platform for further discussion. While human rights awareness was seen as important, participants considered these needed to be framed around issues that were important in the Pacific and which were country specific, such as protection and promotion of the rights and freedoms related to language, culture and traditions.

Participants saw options for more effective human rights monitoring through identifying and prioritising areas to be monitored so that the key issues were clear and known to all; including human rights in national development plans; training judicial officers and those exercising judicial functions or responsibilities; and co-ordinating Government efforts more closely with those of civil society.

\section{Culture, Custom and Human Rights}

Participants emphasised that more progress could be made if cultural expression, respect for cultural diversity and promotion and protection of culture, language and tradition were acknowledged as having a particular importance in the Pacific. Having worked hard to maintain cultural identity and tradition during the last three centuries, and having seen the effects of loss of culture, language and tradition in the colonial and other experiences of diverse nations, participants noted there was sometimes a strong resistance to any human rights approach that was seen to be criticising or challenging cultural practices or traditions. This was exacerbated if the challenges were viewed as denigrating a particular culture or people.

23 Ibid, 20. 
A related and explicit concern in each country was the lack of understanding of what exactly human rights (and responsibilities) entailed, particularly in a globalised world. Specific issues identified include the general perception of human rights as a Western concept that is incompatible with culture and religion, and that the introduction or imposition of human rights to villages would erode familial and cultural values, and promote indiscipline amongst youth.

Recent research on custom law (operated predominantly through traditional Pacific systems) and human rights is helpful. ${ }^{24}$ There is a desire for more dialogue since custom law is the most significant existing mechanism for human rights protection and promotion in many small states. In some islands it is the only meaningful mechanism in the reality of day-to-day life. This clearly has implications for dialogue on possible regional human rights mechanisms.

\section{$V$ KEY CONSIDERATIONS FOR DIALOGUE ON REGIONAL HUMAN RIGHTS MECHANISMS}

Participants at the Symposium noted the variety of options for progressing discussion about regional human rights mechanisms. These options need thorough and systematic consideration across the region. Papers presented by participants at the Symposium show that such options include: ${ }^{25}$

(1) A human rights desk at the PIF Secretariat (which could offer services to Governments of the region);

(2) A regional human rights commissioner and commission;

(3) A human rights charter for the region;

(4) Co-operative delivery of human rights services across the region; and

(5) Assistance from regional human rights organisations such as the Asia Pacific Forum of National Human Rights Institutions.

Whichever option, or set of options, is preferred, insights from the research and dialogue project about national institutions has shown that meaningful regional dialogue will be contingent upon a number of important and interrelated factors.

\section{A The Process}

Participatory processes, which have meaning across the region and within states and territories, are essential and the rights-based approach offers a methodology for ensuring meaningful

24 E Durie Converging Currents: Custom and Human Rights in the Pacific (New Zealand Law Commission, New Zealand, 2006).

25 See for example Kathryn Hay "A Pacific Human Rights Mechanism: Specific Challenges and Requirements" in this volume. 
participation and dialogue. Evaluation of these processes should be planned and carried out at all stages. In order to be credible, participation by diverse groups is likely to be critical including representation of political leaders, government administrators, the judiciary, civil society, traditional leaders, religious leaders, and regional actors. There will be a particular need to ensure proper representation of those affected by key human rights issues in the region including women, disabled people, and those living with HIV/AIDS.

\section{B Support for Existing National and Regional Human Rights Machineries}

The links between national and regional human rights machineries need thorough consideration in light of the history of the region. Pacific peoples have regional relationships that in some cases are many hundreds of years old. Relationships between modern states are not unconnected to relationships founded between peoples over the many years before colonisation and the more modern forms of the state in different countries. These relationships also influence perceptions of regional human rights mechanisms, in particular, how these give expression to those relationships and how these might support or challenge them.

Strong national machineries will foster stronger regional machineries and vice versa. However, the dialogue experience suggests there may be resistance to regional mechanisms if national mechanisms which are already under-resourced are not also supported. This suggests that work will need to take place alongside efforts to strengthen the judiciary and provide support for the courts.

Developments should be premised on assisting small Pacific states to build human rights mechanisms best suited to their own broad circumstances. Experience from dialogue on national human rights mechanisms suggests that attempts to impose "template mechanisms" from elsewhere will either be resisted or will fail. While there is interest in mechanisms from other regions in the world, consultations consistently show that there is a desire for the Pacific to be able to give its own unique expression to such mechanisms. ${ }^{26}$

\section{Human Rights Promotion}

If a regional human rights mechanism is to be effective, human rights must have meaning and relevance to people of the region. Measures to promote human rights, including human rights education, must continue to be a priority in order to build knowledge and awareness at village and island as well as local, national and political levels. Human rights education should foster a stronger civil society which, together with governments, sees meaning and purpose in regional mechanisms for promotion and protection of human rights.

There are, however, challenges in carrying out human rights education particularly outside formal educational settings and risks in perceiving educational institutions as the principal site for

26 See, for example, PIF Members Regional Workshop, above n 2 and Liddicoat, above n 3. 
promotional activities. This suggests that scoping work on regional mechanisms will need to take into account existing human rights promotion activities (both those underway and planned) and consider the resources that might be needed to support any further work.

\section{Advocacy from Diverse Pacific Leaders}

Existing human rights movements and organisations working on thematic human rights issues such as women's human rights, the rights of people with disabilities, children's human rights, and indigenous rights already operate regionally. The experience and leadership of these organisations should be part of any dialogue about a regional human rights mechanism. There are a significant number of organisations and individuals that have considerable experience at working regionally. These experiences might usefully be considered in any dialogue about regional human rights mechanisms.

\section{E The Importance of Language, Culture and Tradition to Pacific Peoples}

Dialogue and research needs to carefully delineate between cultural sensitivity and cultural relativism in the articulation of human rights. This is critical to ensuring that dialogue addresses the concerns of some that human rights are a Western construct and threaten custom and tradition in the Pacific. Such dialogue is necessary to encourage a unique Pacific expression of a system for protection of human rights that does not derogate from international minimum human rights standards. This is relevant to the possible working of any regional mechanisms. As noted by one commentator: ${ }^{27}$

The rigidity of an institutional model, characterised by conflict and opposition, also makes it difficult to achieve equilibrium between the concepts of universal human rights norms and island custom .... The cultural diversity between Pacific Islands means that any regional rules on human rights would also have to be adapted and interpreted in line with national culture. This poses a threat to gaining consensus on human rights issues...

\section{F Relationships Between Aid Donors and Small Pacific States}

The Pacific region is a significant recipient of aid development funds. Over the last 25 years approximately US $\$ 17$ billion has been invested in the region, with mixed results. ${ }^{28}$ Donors have diverse approaches to aid development and these approaches have changed significantly over the

27 J De Blaauw "Human Rights at a Crossroad? Towards an institutionalised regional human rights framework for the Pacific" (2008) 12 Just Change 18.

28 S Pollard "Capacity Development: Pacific Choice" (Pacific Co-operation Foundation Seminar, Wellington, New Zealand, June 2008). 
last 25 years. ${ }^{29}$ The diverse approaches to aid development create issues for Pacific states and for those in communities who are carrying out aid development work including different methods of programme delivery, reporting, monitoring and evaluation, cooperative or violation-based models of problem identification and remedy, and skills recognition and development.

Dialogue about regional human rights mechanisms gives rise to issues for both donor agencies and Pacific states. For donor agencies, such issues include whether and, if so, how, to support such dialogue, the effects on existing aid programmes, and the implications of such dialogue for their own organisations. For recipient states, concerns will no doubt arise as to whether this new dialogue will result in increased demands by donors for human rights mechanisms and accountability within states and, if so, how this will affect states' capacity and capability to meet donor conditions.

There are risks that proposals for related aid development programme work will be underscoped. Technical and financial assistance and support from regional and international organisations, such as United Nations offices and donor agencies, which work both nationally and regionally, is critically important. However, scoping work on regional mechanisms should ensure that initiatives are Pacific-led, draw upon and nurture existing Pacific capacity and capability, and ensure that assistance from outside the region works with and alongside the priorities in Pacific contexts.

\section{G Consider Innovative Approaches based on Regional Experience}

As with options for national human rights mechanisms, regional mechanisms can take a variety of forms. These forms are not mutually exclusive and it is quite possible that the form of any regional mechanism will develop and evolve over time. It can be argued that at least three forms of regional human rights mechanisms already exist. These include: ${ }^{30}$

(1) The PIF Secretariat, which is in the process of establishing a specific human rights position;

(2) Regional civil society organisations including the Regional Rights Resource Trust, Pacific Islands Association of Non-Governmental Organisations and the many other organisations which operate on a regional basis; and

(3) The Asia Pacific Forum of National Human Rights Institutions.

While scoping work is carried out on possible regional mechanisms, existing regional organisations should be kept in mind as these may offer options for development of future

29 Stephen P Marks "The Human Rights Framework for Development: Seven Approaches" (Boston Harvard School of Public Health, Francois-Xavier Bagnoud Centre for Health and Human Rights, Massachusetts, 2003).

30 See www.asiapacificforum.net (accessed 1 June 2008). 
mechanisms. For example, scoping work on regional mechanisms might usefully take into account the research and dialogue on national institutions, which indicates that it is possible to "nest" mechanisms in other institutions with plans for eventual separate identity, functions and powers.

Functions and powers might also develop and expand over time, both as capacity is established and competency and confidence grows. It may be possible for the PIF Secretariat to offer human rights assistance to PIF countries in a variety of ways, with this support providing a foundation for the delivery of more services in a diversity of ways based on proven performance. Over time, this might lead to a separate institution. Finally, the Asia Pacific Forum's Advisory Council of Jurists might also provide a useful model when considering the options for engaging Pacific jurists in regional initiatives or mechanisms. ${ }^{31}$ Scoping work might therefore usefully consider an incremental, perhaps even a progressively staged approach, to the growth and development of a regional human rights mechanism.

\section{CONCLUSION}

Pacific states are free to give their own unique expression to both the international standards for national human rights mechanisms and regional mechanisms for promotion and protection of human rights. However, the opportunities to do so exist in relation to an international human rights framework which needs to more closely consider the particular resource constraints, or the challenges of distance and capability, which are frequently faced by Pacific states. This paper has explored issues and concerns revealed in research and dialogue about national human rights machineries in small Pacific states. These issues and concerns may assist in wider discussions about regional human rights mechanisms in the Pacific.

31 The Advisory Council of Jurists is a group of eminent jurists that advises the Forum on aspects of international human rights law. See www.asiapacificforum.net/acj. 
